\title{
O Processo Penal como Situação Jurídica: ANálise do IDEAl PARa o REAL de Bülow a GOLDSCHMIDT
}

\author{
RAFAel Francisco França
}

Departamento de Polícia Federal - Brasil

\section{Milton Gustavo Vasconcelos Barbosa}

Advogado - Brasil

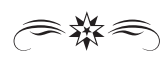

\section{RESUMO}

Trata o presente trabalho sobre a evolução dos entendimentos sobre o processo, com ênfase nos estudos de Bülow e Goldschmidt. As análises feitas sobre o processo penal como relação ou situação jurídica são importantes para a investigação criminal, pelo que este estudo destaca a percepção de Goldschmidt acerca do processo penal como uma guerra, como um jogo (Calamandrei).

Palavras-Chave: Processo. Bülow. Goldschmidt. Relação Jurídica. Situação Jurídica.

\section{INTRODUÇÃ̃o}

Conforme pode ser notado pela análise das teorias que definem a evolução do estudo do processo, é possível apontar que este instituto não foi desenvolvido para ser estanque e imutável. Variou, sim, com a organização do Estado. Em relação ao processo penal, ainda maior a necessidade de concentração ou não de poder para manutenção de situações favoráveis a este ou àquele grupo social.

De tal maneira, as adaptações por que passou o direito processual penal são oriundas de pressões advindas de interesses sobre o controle exercido pelo direito penal nas sociedades ao longo dos séculos, pelo que as conquistas para o aperfeiçoamento das instituições são fruto de embates e disputas para manutenção do poder. 
Analisar o processo penal como único meio de aplicação da pena seria tarefa fácil dentro de um contexto perfeito, ou seja, se os ideais de justiça e verdade pudessem ser comprovados ao final da ação penal, na sentença e na execução. No entanto, já se pode apontar que, na prática, o processo penal não funciona desta maneira.

Assim, pretende-se com este trabalho demonstrar que a controvérsia, ou evolução de conceitos, em relação ao processo como relação jurídica (Bülow) ou como situação jurídica (Goldschmidt) revela muito mais que simples determinação de conceitos abstratos, haja vista as relações de poder que são traduzidas através do processo penal. Cabe questionar, também, o que leva ao Estado, através da acusação, a colocar em andamento, validamente, o órgão jurisdicional para exercer o poder de fazer penar.

A relação processual penal (mesmo que encarada como situação jurídica) é regida pelo princípio da necessidade, devendo ser pensado sobre a pretensão acusatória que rege a ação penal e o próprio processo dentro do conceito de situação instável e sujeita a influências "externas" (não previstas na lei, por assim dizer).

\section{O Ideal. Processo como Relação Jurídica}

Levar à apreciação de tribunais as dificuldades em obter, por si, um direito que lhe assistia foi o meio admitido ao particular pelo Estado com a retirada do poder de composição dos danos advindos do delito das mãos da vítima e de seu grupo. Afinal, a figura de um terceiro alheio ao conflito que se forma entre ofendido e ofensor trouxe a racionalização dos conflitos e a consequente limitação da violência comunitária. De tal modo, a eficácia da atividade do juiz provocada pelas partes assenta-se, exclusivamente, no poder do Estado, o que leva a crer que os adversários não atingem um ao outro diretamente, com sua atividade, mas através das decisões do juiz obtidas pelos pedidos a ele dirigidos. (TORNAGHI, 1987, p. 27).

Assim, o processo penal é necessário porque, de antemão, tenta evitar que a vítima ou alguém por ela tome a iniciativa de revidar, o que acarretaria o caos social. A pena é em última análise uma vingança definitiva, que encerra o ciclo de violência recíproca, é uma vingança da qual 
o particular não tem como retorquir. Sem a racionalização dos conflitos proporcionada pelo sistema judicial, a sociedade se consumiria em infindáveis ondas de vinganças e retaliações.

Esta a principal razão para Lopes Jr. deduzir sobre o mais vital princípio a que se deve a existência do processo penal: o princípio da necessidade. É o que preconiza quando aponta que:

Impöe-se a necessária utilização da estrutura preestabelecida pelo
Estado - o processo penal - em que, mediante a atuação de um ter-
ceiro imparcial, cuja designação não corresponde à vontade das par-
tes e resulta da imposição da estrutura institucional, será apurada a
existência do delito e sancionado o autor. O processo, como institui-
ção estatal, é a única estrutura que se reconhece como legitima para
a imposiçãa da pena. (LOPES JR., 2012, p. 85).

De tal modo, o processo penal tem natureza pública. Para a melhor solução dos conflitos entre os particulares é importante que a vítima esteja distante da persecução, que deve ser entendida pelo acusado como exclusivamente estatal. No entanto, e conforme está disposto por Bülow em sua obra "La teoría de las excepciones y los presupuestos procesales", nem sempre foi assim, tendo em vista que, até a metade do século XIX, o processo tinha caráter meramente adjetivo pelas influências da concepção romana sobre os conceitos de ação e de processo.

Interessa, portanto, desenvolver o tema a partir do entendimento trazido por Bülow sobre as mudanças necessárias na natureza do processo, mesmo que se tenha em mente que tal autor tratava de questóes envolvendo o processo civil a partir de sua relação com o direito material (direito civil, causa posta em disputa no processo).

Para Bülow (1964, p. 2 e ss.), as concepções trazidas pelos romanos permaneceram válidas através do período medieval. Para o autor, o processo era concebido superficialmente, entendido como uma série de atos do juiz e das partes. Para os romanos, a relação de direito material e o processo eram tratados como uma relação jurídica unitária.

Esta também é a opinião de Tornaghi, quando diz que:

$\mathrm{Na}$ verdade, a concep̧ão do processo penal como relação jurídica obedece a uma razão de conveniência e corresponde às conclusões de uma elaboração cientifica. Doisfatores, portanto, convergiram para 
que ela fosse acolbida: a reação dos que, nos séculos XVIII e XIX, combateram a estrutura desumana do processo penal, e a produção literojurídica dos autores que chegaram, no campo do processo civil, a concluir que ele é uma relação de direito. O procedimento de tipo inquisitório, iniciado na Roma imperial com o processo extraordinário e vulgarizado a partir do século XII, era mais propriamente um inquérito seguido de uma sentença do que o judicium do Direito Romano clássico. Embora ditado por louváveis intenções, a verdade é que ele degenerou a ponto de fazer do acusado mero objeto do processo. (TORNAGHI, 1987, p. 2).

Como o direito processual não tinha autonomia enquanto ciência, a ação foi por longo período considerada como direito penal em movimento. Importa deduzir que, antes de Bülow, foram feitos importantes avanços por parte de Windscheid e Muther, isso entre 1856 e 1857 . Esses pensadores trataram de romper com o vínculo existente entre ação e direito material, não sendo mais concebível que se tratasse meramente do direito de pedir em juízo algo devido.

Por assim dizer, o rompimento tornado possível por Windscheid e Muther pode ser dividido em dois estudos sobre a ação: o primeiro tratou de trabalhar o conceito de ação como pretensão traduzida em juízo; o segundo, abordou o caráter público da ação ao afirmar seu direcionamento ao Estado. As mudanças trazidas por esses autores jogaram luz sobre a doutrina processual e levaram à formação de novos conceitos sobre a relação processual a partir de então.

Segundo Coutinho (1998, p. 145), a ação processual penal é um direito potestativo de acusar, público, autônomo, abstrato, mas conexo instrumentalmente ao caso penal. Tal entendimento não existia até as conclusões de Windscheid e Muther sobre tal direito, devendo ser observada a importância destes trabalhos para as conclusões de Bülow.

Para Bülow, e conforme exposto por Aragoneses Alonso (1997, p. 206), como o processo é uma relação jurídica que se estabelece entre as partes e o juiz (Estado), possui problemas análogos às demais relações jurídicas; dentre eles, os necessários pressupostos para formação e desenvolvimento do processo, tido, então, como uma relação jurídica processual a partir daí. As conclusões a que se chegou Bülow são claramente direcionadas ao processo civil, não podendo ser aplicadas ao direito processual penal. Todavia, não se podem desconsiderar os avanços alcançados pela teoria do processo como relação jurídica. 
Também importante notar que Chiovenda, citado por Tornaghi (1987, p. 5), infere que, antes de se julgar o pedido de atuação da lei, é necessário examiná-lo, resultando, daí, uma situação de pendência no decurso da qual não se sabe se ele é ou não fundado. E segue afirmando que, como não é possível saber se há ou não condições de se dar início ao processo, as partes podem apresentar suas razões enquanto perdurar o estado de pendência, o que acaba por acarretar para elas direitos e deveres. Ou seja, Chiovenda aduz que o processo civil contém uma relação jurídica. Essa teoria entende que o processo é uma relação de direitos e obrigações recíprocas, portanto, uma relação jurídica, que se estabelece entre o juiz e as partes, vinculando-os reciprocamente. Assim, o processo, conforme Gimeno Sendra (1981, p. 159), é um conjunto de vinculações jurídicas existentes entre as pessoas que participam do processo.

É dever citar que, para Bülow (1964, p. 2 e ss.), o processo é relação jurídica que tem sua força motriz inicial no direito de ação, mas que se diferencia das demais porque avança gradualmente e o faz passo a passo. Essa uma das características da relação processual por Bülow: seu caráter evolutivo. Segundo tal autor, os estudiosos do processo, até a época em que sua monografia foi escrita, deram demasiada importância ao aspecto externo, evolutivo, isto é, ao procedimento, descurando o conteúdo, a relação jurídica, na qual o processo consiste: relação de Direito Público, que se desenvolve gradualmente entre juiz e as partes.

Para Bülow, portanto, a relação jurídica processual encontra-se em constante movimento e transformação, o que seria diferente no que diz respeito às relações de direito privado, as quais se encontram em debate e estão plenamente concluídas. Neste mesmo momento, a relação jurídica processual se encontra em "gestação". Conclui-se que a chamada relação jurídica processual se "prepara” por meio de atos dos particulares, os quais dirigem a contenda ao poder jurisdicional do Estado.

Mas, quando se formaria tal "relação jurídica processual" por esta concepção? Justamente por ser uma relação jurídica, o processo teria que obedecer a regras, as quais seriam diferentes daquelas que dessem origem à relação de direito material (litígio). Por aí, conclui-se que não se confundem a relação processual com a relação de direito material, com a relação litigiosa. 
$\mathrm{O}$ aperfeiçoamento da relação de direito material que permite afirmar sobre a possibilidade de surgimento da relação processual ocorre antes desta. Por outro lado, o aperfeiçoamento da relação processual surge com a contestação da lide, sendo que o Estado (o tribunal) assume a obrigação de decidir e as partes se comprometem a colaborar e a se submeter aos resultados de tal atividade comum. Caso seja entendido que não é o caso de formação da relação jurídica, por ausência de seus pressupostos, não se dá início ao processo, embora subsista o direito material.

Vale ainda salientar que, conforme Lopes Jr. (2012, p. 85), o Direito Penal é despido do poder de coerção direta, ao contrário do que ocorre no direito privado. Se há outros meios para a cobrança de uma dívida, e se o devedor aceita pagá-la, não há motivos para recorrer ao Poder Judiciário para satisfazer pretensão.

Dessa forma, para Bülow (1964, p. 2 e ss.), o processo é uma relação jurídica autônoma, independente do direito material, pública pela presença do Estado, o qual é detentor da jurisdição a quem se direciona a ação, complexa (em constante movimento e transformação), estando dividida em etapas, embora mantenha sua unidade. Por se tratar de uma relação de direito público, o processo e seus pressupostos não devem ser deixados à mercê da vontade das partes litigantes, isso porque não se trata de um ajuste entre entes privados, não sendo prevalentes os interesses individuais. Trata-se de ato realizado com a ativa participação do Estado, com requisitos coativos e muitas vezes absolutos.

Embora a relação jurídica processual seja independente do direito material, não se pode concluir que seja possível estabelecer uma demanda infundada, sem embasamento em uma relação jurídica de direito material que se alega. Por isso, estabelece-se que são relação autônomas, mas não completamente independentes. Sendo assim, não há como não reconhecer a importância do desenvolvimento do conceito sobre a relação jurídica processual, devendo ser observado que um dos mais importantes avanços em matéria processual foi o fortalecimento do conceito de parte no que tange ao acusado, tido, anteriormente, como objeto da acusação. 
Assim, ao relatar sobre as agruras do processo penal medieval ${ }^{1}$, Tornaghi aponta que:

Especialmente no que respeita ao processo penal, ao contrário do que acontecia nas ordenações antigas, as relações entre o acusado, o acusador e o juiz são reguladas em lei, tornam-se relações jurídicas em que se vêem os direitos, as faculdades, encargos e obrigações de cada um. Destarte, o acusado já não é mero objeto do processo, senão que nele aparece como verdadeiro sujeito de direitos, vinculado à determinações da lei e não à discrição do juiz. (TORNAGHI, 1987, p. 13)

Da mesma forma, também é devida à concepção do processo como relação de direito (relação jurídica) a formação de embrião para o desenvolvimento e fortalecimento da teoria de nulidades processuais, conforme também apontado por Lopes Jr. (2012, p. 99).

Evidenciou-se, também, que o processo é uma via de mão dupla, em que as partes têm direito à prestação jurisdicional, assim como o juiz é obrigado a conduzir a relação processual até o final com a publicação de uma sentença. Conforme Tornaghi:

E o poder dispositivo das partes influi no processo na medida em
que isso é consentido pelo interesse público do Estado. Cumpre não

1 Cita o mencionado autor que: "Depois de haver sido tratado no Direito Grego e no Romano como pessoa, sujeito de direitos, o acusado, por influência dos costumes bárbaros, passou a ser visto como simples coisa, mero objeto do processo. Arrancado do lar, sem qualquer explicação, era levado a uma enxovia que, dali por diante, iria ser o esquife de sua aspirações e o túmulo de seus anseios. Sonhos que sonhara, projetos que concebera, desejos que acalentara, tudo ali encontrava o termo final. $\mathrm{O}$ aconchego familiar desaparecia. E se ele saía da masmorra em que definhava era para ser conduzido à presença de um juiz que lhe fazia perguntas vagas sobre fatos que nem sempre conhecia. Não alcançando o objetivo das indagações e a correlação entre elas, era levado a responder ao que sabia e ao que ignorava. Ainda quando dissesse a verdade, não se livrava da acusação de estar mentindo ou de haver caído em contradição. Se respondia com firmeza era tachado de audacioso e petulante; se tremia era tido como delinquente confesso. Essa interpretação de suas atitudes ainda mais contribuía para aumentar-lhe a confusão, perturbando-lhe a mente já cansada pelo número e pela diversidade das perguntas que se sucediam em atropelo. A partir daí, já não se lembrava nem do que havia dito nem do que realmente acontecera. $\mathrm{E}$ fraquejava, cedia ao pavor. Passava a negar a verdade, entrava pelo reino da fantasia e da imaginação. Ou emudecia. Uma só preocupação o dominava: dizer o que o juiz quisesse ouvir e livrar-se daquela tortura. Deslembrado do que já havia dito, temia expor-se ao perigo de contradizer-se. Percebia que à medida em que o interrogatório se prolongava, mais crescia a prevenção do julgador e aumentava o perigo de ser condenado. Ao fim da inquirição, que antes parecia um entrevero do que um ato processual, era mandado apodrecer no fundo de um calabouço escuro e sufocado. Só o tiravam dali para acareá-lo com pessoas que ele nem sempre tinha visto e cujos depoimentos não lhe eram mencionados. E não se lhe havia manifestado o teor da acusação. Se o que os algozes desejavam era uma confissão, ele terminava por fazê-la, verdadeira ou falsa, contanto que se libertasse daquele tormento e ainda que a admissão de culpa lhe pudesse trazer uma condenação à morte. Morte aliás redentora, que o liberava de um processo iníquo e de um juiz verdugo." Op. cit. p. 3. 
elevar o juiz a dono do processo, nem rebaixar as partes à situação de sujeitos meramente passivos; e vice-versa, é preciso não reduzir o juiz a um títere, boneco movido por meio de cordóes ou engonços pela vontade das partes. (TORNAGHI, 1987, p. 17)

Ao ser acionado o poder jurisdicional e sendo preenchidos os pressupostos da relação que se forma, independente da relação de direito material, as partes vinculam-se ao juiz, não podendo simplesmente procurar outro que lhes forneça diretamente o que se pleiteia na ação. No entanto, apesar de imprescindível para o estudo do direito processual penal, a teoria de Bülow sobre a relação processual foi contestada por se tratar de equívoco acreditar que no processo penal há a formação de uma relação jurídica de direitos e obrigações ideal, em que se comunga de um autêntico processo de partes.

\section{O Real. Processo como Situação Jurídica}

Neste ponto, antes de entrar no debate provocado por Goldschmidt com as observações feitas sobre o processo, interessa indicar que as relações entre as partes não se constituem através dele; pelo contrário, e conforme Aragoneses Alonso (1997, p. 246), interrompem-se por causa deste mesmo processo, sendo substituídas por situações jurídicas.

É preciso entender, portanto, que Bülow concebeu sua teoria contemplando em especial o processo civil e que posteriormente as categorias por ele estudadas e desenvolvidas foram transpostas para o processo penal. A teoria do processo como relação jurídica tem uma lógica impecável, apontando para um sistema perfeito de direitos e obrigações entre as partes. (LOPES JR., 2008, p. 193). E é exatamente contra a perfectibilidade ilusória da teoria de Bülow que recai a crítica de Goldschmidt. Em seu livro Prozess als Rechtslage de 1925 (LOPES JR., 2008, p. 193), expõe sua teoria do processo como situação jurídica, que marcaria definitivamente a separação entre processo civil e processo penal, assinalando a completa impossibilidade de uma teoria geral do processo.

Para Goldschmidt, o Estado tem o poder soberano de punir seus súditos, porém este poder estaria condicionado à submissão destes a um processo judicial. O Estado é, nesse sentir, o titular do direito de punir e titular da jurisdição, que é exercitada por meio dos juízes (GOLDSCHMIDT, 1935, p. 23). O direito de aplicar a pena é um direito potestativo do Estado, e precede à ação 
penal, tendo sua raiz no fato delituoso. Ocorrido o crime, nasce para o Estado o poder de punir, que só poderá ser posto em prática após a sentença. Portanto, a pena não é decorrência natural do delito (GOLDSCHIMDT, 1935, p. 26), sim o direito de punir. A pena é decorrência deste direito, e surge depois que o Estado segue o caminho do processo penal e obtém uma sentença judicial de fundo, ou mérito, que lhe permite o exercício deste direito.

O acusador oficial ou o querelante não pleiteia um direito próprio, como no direito civil, já que o direito de punir não existe à margem do processo. Requerem os acusadores que o Estado-juiz exercite um direito que lhe é próprio, qual seja, o de condenar o réu e executar a sentença. Nesse sentido, assinala Goldschmidt, que é impróprio se falar em "ação penal", já que ação é demanda judicial por proteção judicial a um direito que existe de forma autônoma ao processo. $\mathrm{O}$ conceito de ação é, portanto, próprio do direito processual civil e não encontra analogia no processo penal. Neste há a acusação penal, via pela qual se informa o nascimento do direito dever de punir, e exige que este seja levado a efeito, ou nas palavras de Goldschmidt:

La situación jurídica del querellante es completamente otra que La del actor. No hace valer como este, un derecho propio y pide su adjudicación, sino que afirma El nacimiento del derecho judicial de penar y exige el ejercicio de este derecho al mismo tiempo representa un deber. Tal es el verdadero sentido del 'j'accuse."....) La exigencia en sentido de derecho material civil, que generalmente es objeto de un pleito, no tiene analogía en el proceso penal. La llamada exigencia punitiva no existe, porque no hay derecho de penar fuera del proceso y porque este derecho es un poder estatal, pero no una exigencia. (GOLDSCHMIDT, 1935, p. 28).

Nesta dimensão, o Estado-juiz não mais pode participar da relação processual na condição de parte. A acusação parte do acusador que deve prová-la, não por outra razão surge no processo penal a figura do acusador oficial, no Brasil, o Ministério Público. A existência de um órgão com o fito de manejar a acusação pública é fundamental para o sistema processual acusatório, pois permite a imparcialidade do juiz. A partir disto, o juiz não mais participa da produção da prova, e não se contamina com o frenesi das partes, mantêm-se por isto apartado do conflito. A existência de uma instância alheia ao conflito e destinada a resolvê-lo é tão importante, que alguns antropólogos veem aí o mais importante marco civilizatório das comunidades humanas. (GIRARD, 1990, p. 30). 
Além da inadequação do termo "ação penal", Goldschmidt defendeu outras razões que impossibilitam a existência de uma teoria conjunta do processo. Entre estas criticou a concepção de processo como "relação jurídica" e a consequente existência de direitos e deveres entre partes e juiz e os pressupostos processuais, defendidos na obra de Bülow. As ideias concebidas por Bülow para o processo civil e transpostas para o processo penal davam a errônea compreensão de que "el proceso implica una cooperación de voluntades encaminadas as mismo fin, a la aplicación de la ley por médio de la sentencia" (GOLDSCHMIDT, 1935, p. 45). Para Goldschmidt, não há relações de direitos e deveres entre as partes, tampouco colaboração para um mesmo fim, e os pressupostos processuais são na verdade pressupostos de uma sentença de mérito, conforme se lê:

... he impugnado la teoría de la relación jurídica procesal. Ésta no tiene valor ninguno. Las condiciones formales que, segün Bülow, figuran como 'presupuestos' del proceso, no lo son en verdad, puesto que han de substanciarse en el proceso mismo. Más bien son presupuestos de una sentencia sobre el fondo. Tampoco el concepto de la relación jurídica procesal tiene transcendencia con respecto a su contenido, puesto que el deber del juez de conocer la querella, se basa en la obligación estatal de administrar justicia, $y$ a las partes no incumben obligaciones procesales, ni frente as Juez, ni mutuamente. Es cierto que es la obligación estatal de administrar justicia hay correlatividad con supuestos derechos subjetivos de las partes, pero éstos también de mera indole pública, y no hay ni siquiera que reconocer un derecho potestativo del querellante de constituir la relación jurídica procesal, sino sólo una facultad de hacer aparecer la obligación estatal de administrar justicia... (GOLDSCHMIDT, 1935, p. 43).

Portanto, nega Goldschmidt a existência de direitos e obrigações entre as partes entre si e entre o juiz (GOLDSCHMIDT, 2006, p. 16). As partes não são obrigadas a dar sua contribuição para o desenrolar da marcha processual. Ao invés de obrigações, as partes têm cargas processuais, que são atos que devem ser realizados pelas partes a fim de evitar um prejuízo processual (LOPES JR., 2008, p. 196). No processo penal, as cargas não são distribuídas, pois a responsabilidade de provar a viabilidade da acusação é atribuída exclusivamente ao acusador. Não há, portanto, ônus para a parte que se omite à prática de um ato importante no processo, o que ocorre nesses casos é o aumento do risco de uma sentença desfavorável. Como dito, todas 
as cargas processuais (no processo penal) pertencem à acusação, que tem que dispensá-las, sob pena de não conseguir provar a acusação e criar a perspectiva de uma sentença desfavorável. A defesa não tem qualquer carga no processo penal, visto que o réu encontra-se amparado pelo princípio constitucional da presunção de inocência, porém, ao negligenciar um ato importante a defesa perde uma oportunidade de obter a captura psicológica do Juiz. Então, a defesa aumenta o risco de uma sentença desfavorável e diminui a expectativa de uma sentença favorável. (LOPES JR., 2008, p. 196).

Portanto, Goldschmidt desvela a verdadeira fenomenologia do processo, em que um erro ou omissão, assim como o acerto e a diligência, podem transformar completamente a situação da acusação e da defesa no processo. A teoria do processo como "situação jurídica" demonstra a incerteza de que se revestem os processos judiciais. Sua teoria destrói a ilusão platônica de segurança jurídica, e mostra que o processo judicial é como a guerra, nenhum direito está absolutamente resguardado! A certeza é uma característica do direito material, que ao ser colocado in litis, passa ao terreno do incerto. Goldschmidt também demonstra que a unidade do processo está condicionada a seu objeto, a pretensão penal, e não à relação jurídica artificialmente criada por Bülow. $\mathrm{O}$ processo não conhece unicidade, é um complexo de situações, ou chances, que se desenrola frente aos atores, que têm que aproveitá-las da melhor forma possível. Neste cenário de incertezas, a única garantia que o cidadão pode pretender é o respeito pelas regras do jogo. (LOPES JR., 2008, p. 203).

\section{Conclusões}

Não se pode entender o trabalho de Goldschmidt senão a partir dos conceitos desenvolvidos por Bülow com base na evolução do processo de relação para situação jurídica. Embora sejam fundadas as críticas feitas aos pressupostos processuais e à teoria que lhes trouxe à baila, considera-se que Bülow fez com que se passasse a pensar o direito processual de outra forma, tendo contribuído para que fosse encarada a relação que se forma entre juiz e partes de forma tridimensional, fazendo a correta distinção entre processo e procedimento. Ainda, foi ele quem inaugurou o estudo do processualismo científico, passando a entender o processo pelo prisma do direito público. 
Além disso, não se pode descartar a importância em se passar a encarar o acusado como parte e, não, como objeto do processo penal, conquista relevante para a formação de outras garantias, tais como imparcialidade do julgador e contraditório.

Todavia, o que se leva em consideração é a realidade no ato de instruir o processo penal, em como ele se forma e porque está também sujeito às influências externas. Conforme será exposto, pugna-se pela máxima segundo a qual o processo penal não é hermeticamente fechado, imune às mencionadas influências.

As teorias do processo penal como "relação jurídica" e como "situação jurídica” tiveram enorme importância para a delicada compreensão do direito processual. Porém, por razões evidentes (época em que foram formuladas), ambas trataram do processo como um sistema hermético, em que as influências externas não existiriam. Ou seja, a possibilidade da contaminação das decisões judiciais pelo escândalo que se forma em torno dele foi totalmente desprezada por Bülow e Goldschmidt.

Compreendemos o sistema judicial como a racionalização da vingança comunitária (GIRARD, 2011, p. 127), e concordamos com Aragoneses Alonso, quando este afirma que a privação temporária da liberdade do condenado se dá para que ele possa gozá-la de maneira plena em um momento posterior. (ARAGONESES ALONSO, 1997, p. 37). Quando ocorre o crime, imediatamente se segue o escândalo. O escândalo, do grego Skándalon (GIRARD, 2011, p. 108), contamina toda a comunidade como se fora uma epidemia. A noção de culpado ou de inocente se dá pelo olhar comunitário. O juiz, o promotor, o advogado e até mesmo o réu, podem ser também contaminados pelo "inconsciente persecutório", ou seja, pela absoluta convicção de culpa que surge como uma onda e nas sociedades primitivas levava ao linchamento unânime. Quanto maior o escândalo, maior a chance do juiz ser contaminado pela comunidade, por isto, em crimes violentos ou de grande repercussão, os juízes geralmente determinam a prisão preventiva do acusado e têm uma enorme tendência em condená-lo. O juiz, que deveria ser o garantidor do cidadão contra a massa enfurecida em que se converteu a comunidade, adere à multidão, tornando-se um dos linchadores. $\mathrm{O}$ ativismo judicial nada mais é do que assunção por parte de alguns magistrados de um compromisso com a violência coletiva. 
Assim sendo, o respeito às regras do jogo é fundamental, não só para que os atores do processo se comportem adequadamente dentro do ritual judicial, mas também para impedir que ajam como os atores de fora do processo.

RAFAEL FRANCISCO FRANÇA

\author{
Delegado de Polícia Federal. Especialista em Ciências \\ Policiais e Investigação Criminal pela ANP/DFF. Sócio do Ins- \\ tituto Brasileiro de CiênCias Criminais - IBCCrim. Mestre \\ em Ciências Criminais pela PUC/RS. Doutorando em Estudos \\ ESTRATÉGICOS INTERNACIONAIS PELA UFRGS. \\ MILTON GUSTAVO VASCONCELOS BARBOSA \\ Advogado. Mestre em CiênCias Criminais pela PUC/RS. Dou- \\ torando em Ciências Criminais pela PUC/RS.
}

\title{
ABSTRACT
}

\section{The Criminal Proceedings as Legal Situation: Analysis from ideal to actual from Bülow to Goldschimidt}

This paper is about the evolution of the understandings about the process, emphasizing the studies of Bülow and Goldschimidt. Analysis about Criminal Proceedings as relation or legal situation are importants to Criminal Investigation whereby this study highlights the Goldschmidt's perception about the Criminal Proceedings as a war, as a game (Calamandrei).

KEYwORDS: Proceedings. Bülow. Goldschmidt. Legal Relation. Legal Situation.

\section{REFERÊNCIAS}

ARAGONESES ALONSO, Pedro. Proceso y Derecho Procesal. Madrid: Edersa, 1997.

BÜLOW, Oscar Von. La teoría de las excepciones y los presupuestos procesales. Traducción de Miguel Angel Rosas Lichtschein. Buenos Aires: Ediciones Juridicas Europa-America, 1964.

COUTINHO, Jacinto Nelson de Miranda. A lide e o conteúdo do processo penal. $3^{\text {a }}$ ed. Curitiba: Juruá, 1998.

GIMENO SENDRA, José Vicente. Fundamentos del Derecho Procesal. Madrid: Civitas, 1981. 
GIRARD, R. Aquele por quem o escândalo vem. Tradução de Carlos Nougué. São Paulo: Realizações, 2011.226p.

. A violência e o Sagrado. Tradução de Martha Conceição

Gambini. São Paulo: Paz e Terra, 1990.391p.

. Veo a Satan caer como el relámpago.Tradução para o espanhol de Francisco Díez del Corral. Barcelona: Anagrama, 1999. 248p.

GOLDSCHMIDT, James. Problema Jurídicos y Políticos del Proceso

Penal. Madrid: Bosch, 1935.247p. . Teoria Geral do Processo. Leme: Forum, 2006. 170p.

LOPES JR, Aury. Direito Processual Penal. - 9. ed. rev. e atual. - São Paulo: Saraiva, 2012. . In GAUER, R. M. C. (Org.). Criminologia e Sistemas jurídicospenais contemporâneos II. Porto Alegre: EDIPUCRS, 2008. 422p.

TORNAGHI, Hélio Bastos. A Relação Processual Penal. 2 ed., São Paulo: Saraiva, 1987.

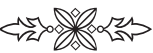

